\title{
The complete mitochondrial genomes of three parasitic nematodes of birds: a unique gene order and insights into nematode phylogeny
}

\author{
Guo-Hua Liu' ${ }^{1,2 \dagger}$, Renfu Shao ${ }^{3 * \dagger}$, Jia-Yuan Li ${ }^{1}$, Dong-Hui Zhou' ${ }^{1}$, Hu Li ${ }^{4}$ and Xing-Quan Zhu ${ }^{1,2^{*}}$
}

\begin{abstract}
Background: Analyses of mitochondrial (mt) genome sequences in recent years challenge the current working hypothesis of Nematoda phylogeny proposed from morphology, ecology and nuclear small subunit rRNA gene sequences, and raise the need to sequence additional mt genomes for a broad range of nematode lineages.

Results: We sequenced the complete mt genomes of three Ascaridia species (family Ascaridiidae) that infest chickens, pigeons and parrots, respectively. These three Ascaridia species have an identical arrangement of $\mathrm{mt}$ genes to each other but differ substantially from other nematodes. Phylogenetic analyses of the $\mathrm{mt}$ genome sequences of the Ascaridia species, together with 62 other nematode species, support the monophylies of seven high-level taxa of the phylum Nematoda: 1) the subclass Dorylaimia; 2) the orders Rhabditida, Trichinellida and Mermithida; 3) the suborder Rhabditina; and 4) the infraorders Spiruromorpha and Oxyuridomorpha. Analyses of mt genome sequences, however, reject the monophylies of the suborders Spirurina and Tylenchina, and the infraorders Rhabditomorpha, Panagrolaimomorpha and Tylenchomorpha. Monophyly of the infraorder Ascaridomorpha varies depending on the methods of phylogenetic analysis. The Ascaridomorpha was more closely related to the infraorders Rhabditomorpha and Diplogasteromorpha (suborder Rhabditina) than they were to the other two infraorders of the Spirurina: Oxyuridorpha and Spiruromorpha. The closer relationship among Ascaridomorpha, Rhabditomorpha and Diplogasteromorpha was also supported by a shared common pattern of mitochondrial gene arrangement.
\end{abstract}

Conclusions: Analyses of mitochondrial genome sequences and gene arrangement has provided novel insights into the phylogenetic relationships among several major lineages of nematodes. Many lineages of nematodes, however, are underrepresented or not represented in these analyses. Expanding taxon sampling is necessary for future phylogenetic studies of nematodes with $\mathrm{mt}$ genome sequences.

Keywords: Mitochondrial genome, Ascaridia, Nematode, Gene arrangement, Phylogeny

\section{Background}

Nematodes (also called roundworms) are an extremely diverse group of bilateral animals with an estimate of 110 million species although only $\sim 25,000$ species have been described [1]. Nematode taxonomy has traditionally been formed from morphology and ecology, e.g. the early

\footnotetext{
* Correspondence: rshao@usc.edu.au; xingquanzhu1@hotmail.com ${ }^{\dagger}$ Equal contributors

${ }^{3}$ Genecology Research Centre, University of the Sunshine Coast, Queensland 4558, Australia

'State Key Laboratory of Veterinary Etiological Biology, Key Laboratory of Veterinary Parasitology of Gansu Province, Lanzhou Veterinary Research Institute, Chinese Academy of Agricultural Sciences, Lanzhou, Gansu Province 730046, People's Republic of China

Full list of author information is available at the end of the article
}

systems proposed by Schneider (1866) [2] on somatic musculature and by Cobb (1919) [3] on stoma armature, and the system proposed by Filipjev (1929) [4] on the presence and absence of zooparasitism. Chitwood (1937) [5] proposed initially the bipartite phylogenetic and taxonomic system based on the presence and absence of phasmids; this system was further elaborated later by Maggenti $(1963,1983)[6,7]$ based on pharyngeal structure and excretory systems. However, due to the lack of homologous characters and informative fossil records, and the extensive convergent evolution, it has been extremely difficult to derive a consistent phylogenetic and taxonomic framework for the phylum Nematoda from morphological and ecological characters [8-12]. In the past two decades,

\section{Biomed Central}


nematode phylogeny and taxonomy have been revised with analyses of the nuclear small subunit (SSU) rRNA gene sequences [12-14]. The current working hypothesis of Nematoda phylogeny incorporated evidence from morphology, ecology and SSU rRNA gene sequence analyses $[13,14]$.

The mitochondrial (mt) genomes of bilateral animals usually contain 37 genes and a control region on a circular chromosome, $\sim 16 \mathrm{~kb}$ in size [15-17]. Sequences of individual $\mathrm{mt}$ genes and whole $\mathrm{mt}$ genomes are widely used to infer phylogenetic relationships among animals at different taxonomic levels $[18,19]$. In a number of cases, arrangement of mt genes has also been used to resolve long-standing phylogenetic relationships that could not be resolved by other means [20-22].

Recently, mt genome sequences have also been analyzed to understand the phylogenetic relationships among nematodes. Kang et al. [23] inferred the Nematoda phylogeny with the mt genome sequences of 25 species; Park et al. [24] and Sultana et al. [25] expanded further the analysis to include 36 and 41 species respectively. A major difference between mt genome phylogenies and the current working hypothesis of the Nematoda is on the relationship among four infraorders: Ascaridomorpha, Rhabditomorpha, Spiruromorpha and Oxyuridomorpha. In the current working hypothesis, Ascaridomorpha, Spiruromorpha and Oxyuridomorpha are in the suborder Spirurina whereas Rhabditomorpha is in the suborder Rhabditina [13,14]. Furthermore, Ascaridomorpha is most closely related to Spiruromorpha, whereas Oxyuridomorpha is sister to Ascaridomorpha + Spiruromorpha + Rhigonematomorph . In the phylogenies inferred from mt genome sequences, however, Ascaridomorpha is most closely related to Rhabditomorpha; in most analyses, Oxyuridomorpha is sister to Ascaridomorpha + Rhabditomorpha, whereas Spiruromorpha is sister to the group that contains Ascaridomorpha, Rhabditomorpha and Oxyuridomorpha $[23,24]$. Due to limited taxon sampling, however, the novel phylogenetic relationships inferred from mt genome sequences in these studies need to be interpreted with caution and further test with more taxa from a wide range of lineages is necessary.

In this study, we sequenced the complete mt genomes of three Ascaridia species in the family Ascaridiidae of the infraorder Ascaridomorpha. Ascaridia species are among the most prevalent and pathogenic parasitic nematodes found in domestic and wild birds and have a worldwide distribution [26]. These Ascaridia species share an identical arrangement of $\mathrm{mt}$ genes to each other but differ substantially from those of other nematodes. We inferred the phylogenetic relationships with the complete mt genome sequences of the Ascaridia species and 62 other nematode species that have been sequenced to date. Our analyses support the close relationship between Ascaridomorpha and Rhabditomorpha, and provide novel insights into other phylogenetic relationships in the Nematoda.

\section{Results}

Mitochondrial genomes of three Ascaridia species

The complete mt genomes of A. galli, A. columbae and Ascaridia sp. (GHL-2012) were 13,977 bp, 13,931 bp and 13,862 bp long, respectively (GenBank accession numbers JX624728, JX624729 and JX624730). Each mt genome contains 12 protein-coding genes, 22 tRNA genes and two rRNA genes on a circular chromosome (Figure 1). As in most other nematodes, atp 8 gene is not present in the mt genome of A. galli, A. columbae and Ascaridia sp. (GHL-2012); all mt genes are transcribed from the same direction. TTT is used as the initiation codon in nad6 gene in the mt genome of A. galli. TTT was previously reported to be the initiation codon for cox2, cytb, nad4, nad3, nad2 and cox3 genes in the mt genome of Strongyloides stercoralis (Strongyloididae), but not for any other Ascaridida nematodes. All of the 12 protein-coding genes have complete termination codons, TAA or TAG. The tRNA genes in mt genomes of A. galli, A. columbae and Ascaridia sp. (GHL-2012) range from 51 to $76 \mathrm{bp}$. The tRNA-Ser ${ }^{(\mathrm{AGN})}$ and tRNASer ${ }^{(\mathrm{UCN})}$ have truncated secondary structures; these two

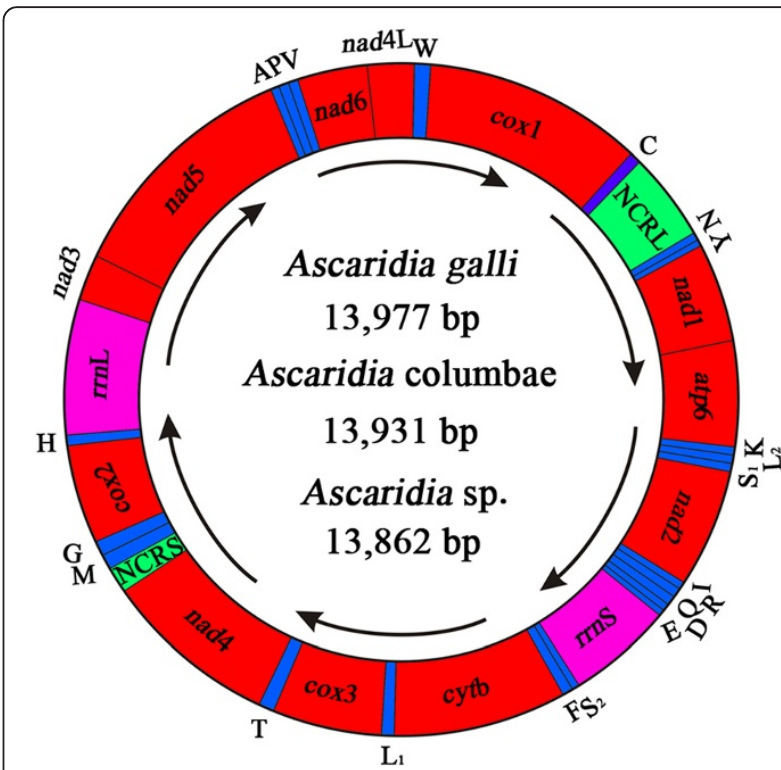

Figure 1 The mitochondrial genomes of three Ascaridia species. All genes are on the same DNA strand and are transcribed clockwise. Protein-coding and rRNA genes are indicated with the standard nomenclature. tRNA genes are indicated with the one-letter code of their corresponding amino acids. There are two tRNA genes for leucine: $L_{1}$ for codons $C U N$ and $L_{2}$ for UUR; and two tRNA genes for serine: $S_{1}$ for codons $A G N$ and $S_{2}$ for UCN. "NCRL" refers to the large non-coding region. "NCRS" refers to a small non-coding region. 
tRNAs lack a DHU stem but possess a TYC loop. In all other 20 tRNA genes, the TYC arm and variable loop are replaced with a TV replacement loop. There are two non-coding regions (NCR) in the $\mathrm{mt}$ genomes of $A$. galli, A. columbae and Ascaridia sp. (GHL-2012) (Table 1).
The longer NCR (NCRL) is between $\operatorname{trn} C$ gene and $\operatorname{trn} N$ gene, and is $610 \mathrm{bp}$ (A. galli), $563 \mathrm{bp}$ (A. columbae) and 566 bp [Ascaridia sp. (GHL-2012)] respectively. The shorter NCR (NCRS) is between nad4 and trnM gene, and is $157 \mathrm{bp}$ (A. galli), $91 \mathrm{bp}$ (A. columbae) and $101 \mathrm{bp}$

Table 1 List of annotated mitochondrial genes and regions of Ascaridia galli, Ascaridia columbae and Ascaridia sp

\begin{tabular}{|c|c|c|c|c|c|c|c|}
\hline \multirow[t]{2}{*}{ Gene/region } & \multicolumn{3}{|c|}{ Position/length (bp) } & \multicolumn{3}{|c|}{ Start/stop codon } & \multirow[t]{2}{*}{ Anticodons } \\
\hline & A. galli & A. columbae & Ascaridia sp. & A. galli & A.columbae & Ascaridia sp. & \\
\hline $\operatorname{cox} 1$ & $1-1563(1563)$ & $1-1563(1563)$ & $1-1581(1581)$ & ATG/TAA & ATG/TAA & $\mathrm{GTG} / \mathrm{TAG}$ & \\
\hline tRNA-Cys (C) & $1565-1620(56)$ & $1565-1620(56)$ & $1562-1616(55)$ & & & & GAT \\
\hline Non-coding region (NCL) & $1621-2230(610)$ & $1623-2183(563)$ & $1617-2182(566)$ & & & & \\
\hline tRNA-Asn (N) & $2231-2284(54)$ & 2184-2241 (58) & 2183-2239 (57) & & & & GTT \\
\hline tRNA-Tyr (Y) & 2286-2344 (59) & $2246-2303(58)$ & $2240-2295(56)$ & & & & GTA \\
\hline nad1 & $2342-3217(876)$ & 2301-3176 (876) & $2298-3167(870)$ & TTG/TAA & TTG/TAA & GTT/TAG & \\
\hline atp6 & $3217-3813(597)$ & $3176-3772(597)$ & $3170-3766(597)$ & ATA/TAA & ATA/TAA & TTG/TAG & \\
\hline tRNA-Lys (K) & $3816-3876(61)$ & $3790-3853(64)$ & $3772-3833(62)$ & & & & $\pi T$ \\
\hline tRNA-Leu UUR $\left(L_{2}\right)$ & 3876-3931(56) & 3853-3907 (55) & $3831-3886(56)$ & & & & TAA \\
\hline tRNA-Ser ${ }^{\text {AGN }}\left(S_{1}\right)$ & 3932-3982 (51) & 3908-3962 (55) & 3887-3939 (53) & & & & $\mathrm{GCT}$ \\
\hline nad2 & $3986-4828(843)$ & $3966-4808(843)$ & $3943-4779(837)$ & TTG/TAA & TTG/TAA & TTG/TAG & \\
\hline tRNA-Ile (I) & $4832-4891(60)$ & 4823-4884 (62) & $4781-4841(61)$ & & & & GAT \\
\hline tRNA-Arg (R) & $4896-4950(55)$ & 4888-4944 (57) & $4845-4900(56)$ & & & & ACG \\
\hline tRNA-Gln (Q) & 4951-5005 (55) & 4945-4998 (54) & 4901-4954 (54) & & & & $T T G$ \\
\hline tRNA-Asp (D) & 5005-5063 (59) & $5011-5070(60)$ & 4971-5025 (55) & & & & GTC \\
\hline tRNA-Glu (E) & $5065-5125(61)$ & $5069-5126(58)$ & $5025-5083(59)$ & & & & TTC \\
\hline$r r n S$ & $5123-5823(701)$ & $5124-5826(703)$ & $5084-5774(691)$ & & & & \\
\hline tRNA-Ser ${ }^{\cup C N}\left(\mathrm{~S}_{2}\right)$ & $5826-5880(55)$ & 5837-5891 (55) & $5781-5835(55)$ & & & & TGA \\
\hline tRNA-Phe (F) & $5883-5939(57)$ & $5898-5953(56)$ & 5841-5897 (57) & & & & GAA \\
\hline cytb & $5964-7067(1104)$ & $5975-7075(1101)$ & $5919-7019$ (1101) & ATG/TAA & GTT/TAA & GTT/TAG & \\
\hline tRNA-Leu ${ }^{\mathrm{CUN}}\left(\mathrm{L}_{1}\right)$ & $7067-7122(56)$ & 7077-7134 (58) & $7020-7075(56)$ & & & & TAG \\
\hline $\cos 3$ & $7144-7914(771)$ & 7154-7918 (765) & 7097-7864 (768) & TTG/TAG & TTG/TAA & TTG/TAA & \\
\hline tRNA-Thr (T) & 7889-7944 (56) & 7899-7956 (58) & $7845-7900(56)$ & & & & TAG \\
\hline nad4 & 7939-9174 (1236) & $7951-9186(1236)$ & $7901-9130(1230)$ & GTG/TAG & ATA/TAG & TTG/TAG & \\
\hline Non-coding region(NCR) & $9175-9331(157)$ & 9187-9277 (91) & 9131-9231 (101) & & & & \\
\hline tRNA-Met (M) & $9345-9407(63)$ & $9288-9352(65)$ & $9232-9294(63)$ & & & & CAT \\
\hline tRNA-Gly (G) & $9407-9462(56)$ & $9355-9410(56)$ & 9296-9351 (56) & & & & TCC \\
\hline $\cos 2$ & $9463-10158(696)$ & $9411-10106$ (696) & $9364-10050(687)$ & TTG/TAG & TTG/TAG & ATG/TAG & \\
\hline tRNA-His $(\mathrm{H})$ & $10163-10218$ (56) & $10113-10167(55)$ & $10049-10105$ (57) & & & & GTG \\
\hline$r r n L$ & $10211-11166$ (956) & 10167-11121 (955) & 10103-11055 (953) & & & & \\
\hline nad3 & 11167-11502 (336) & 11119-11454 (336) & 11053-11391 (339) & TTG/TAA & ATA/TAA & TTG/TAA & \\
\hline nad5 & $11502-13082$ (1581) & $11451-13031$ (1581) & 11394-12968 (1575) & ATA/TAA & ATA/TAG & ATT/TAG & \\
\hline tRNA-Ala (A) & $13085-13139(55)$ & $13031-13085$ (55) & $12968-13022(55)$ & & & & TGC \\
\hline tRNA-Pro (P) & $13140-13197(58)$ & $13094-13149$ (56) & $13026-13082(57)$ & & & & TGG \\
\hline tRNA-Val (V) & $13197-13252(56)$ & $13149-13205$ (57) & 13082-13137 (56) & & & & TAC \\
\hline nad6 & 13253-13687 (435) & $13206-13640$ (435) & 13138-13572 (435) & TाT/TAA & TTG/TAA & TTG/TAG & \\
\hline nad4L & 13702-13941 (240) & 13656-13895 (240) & 13588-13827 (240) & ATT/TAA & GTT/TAA & ATT/TAA & \\
\hline tRNA-Trp (W) & 13919-13976 (58) & 13873-13930 (58) & $13805-13862$ (58) & & & & TCA \\
\hline
\end{tabular}


[Ascaridia sp. (GHL-2012)] respectively. A NCR at this location, i.e. between nad4 and trnM, is also present in the $\mathrm{mt}$ genomes of most other nematodes $[27,28]$.

\section{Gene rearrangement in the mitochondrial genomes of Ascaridia species}

A. galli, A. columbae and Ascaridia sp. (GHL-2012) have an identical gene arrangement in their $\mathrm{mt}$ genomes. The arrangement of $\mathrm{mt}$ genes in these three species, however, is substantially different from those of other nematodes (Figure 2). The mt genomes of the 62 species of nematodes that have been sequenced to date showed 25 types of gene arrangements (GA1-GA25, Figure 2), of which GA3 is the most common type and has been found in 32 species of nematodes. In comparison to the GA3 type, at least three rearrangement events occurred in the Ascaridia species: trnM was translocated, and a block of 11 genes (trnN, trnY, nad1, atp6, $\operatorname{trnK}, \operatorname{trn} L_{2}, \operatorname{trn} S_{1}, \operatorname{nad} 2$, trnI, trnR and trnQ) swapped position with another block of 12 genes (trnG, cox2, $\operatorname{trn} H, \operatorname{rrnL}, \operatorname{nad} 3, \operatorname{nad} 5, \operatorname{trn} A$, trnP, trn $V$, nad6, nad4L and trn W) (Figure 3).

\section{Phylogeny of nematodes inferred from mitochondrial genome sequences \\ Monophylies of the order Rhabditida and the subclass Dorylaimia}

Of the 65 species of nematodes included in the phylogenetic analyses in this study, 54 species were from the order Rhabditida of the class Chromadorea, and 11 species were from the subclass Dorylaimia of the class Enoplea. Both Rhabditida and Dorylaimia were monophyletic in all of the trees inferred with Bayesian, ML and MP methods from concatenated amino acid sequences deduced from the sequences of the $12 \mathrm{mt}$ protein-coding genes. The monophyly of the order Rhabditida was strongly supported with a posterior probability (PP) of 1 in Bayesian analysis (Figure 4), a bootstrapping frequency (BF) of $100 \%$ in ML analysis (Figure 5), and a BF of 94\% in MP analysis (Figure 6). The monophyly of the subclass Dorylaimia was strongly supported in Bayesian and ML analyses $(\mathrm{PP}=1$, Figure 4; $\mathrm{BF}=97$, Figure 5 ), and was moderately supported in $\mathrm{MP}$ analysis $(\mathrm{BF}=67 \%$, Figure 6$)$.

\section{Phylogenetic relationships within the order Rhabditida}

The 54 species of nematodes in the order Rhabditida included in this study were from three suborders: Rhabditina (24 species), Spirurina (26 species), and Tylenchina (4 species). The monophyly of the suborder Rhabditina was strongly supported in Bayesian and ML analyses ( $\mathrm{PP}=1$, Figure 4; $\mathrm{BF}=99 \%$, Figure 5), and was moderately supported in MP analysis (BF $=79 \%$, Figure 6). The Spirurina and the Tylenchina, however, were not monophyletic in all of the three phylogenetic analyses in this study.

Of the 24 species from the suborder Rhabditina, 23 species were from the infraorder Rhabditomorpha and one species from the infraorder Diplogasteromorpha. Species of these two infraorders were most closely related in all of the phylogenetic analyses in this study. The Rhabditomorpha, however, was paraphyletic with respect to the Diplogasteromorpha. Three species from the superfamily Rhabitoidea of the Rhabditomorpha were more closely related to Pristionchus pacificus (Diplogasteromorpha) than they were to the other 20 species from the Rhabditomorpha. The close relationship between the species of the superfamily Rhabitoidea and $P$. pacificus was strongly supported in Bayesian analysis ( $\mathrm{PP}=1$, Figure 4 ), and was moderately supported in $\mathrm{ML}$ and $\mathrm{MP}$ analyses $(\mathrm{BF}=83 \%$, Figure $5 ; \mathrm{BF}=82 \%$, Figure 6). In addition to the Rhabitoidea, three other superfamilies of the infraorder Rhabditomorpha were also represented in our analyses: Ancylostomatoidea (4 species), Strongyloidea (10 species), and Trichostrongyloidea (6 species). The Trichostrongyloidea was monophyletic with strong support in all of the three phylogenetic analyses in this study ( $\mathrm{PP}=1$, Figure $4 ; \mathrm{BF}=88 \%$, Figure 5 ; $\mathrm{BF}=88 \%$, Figure 6). The Rhabitoidea was monophyletic with strong support in Bayesian analysis $(\mathrm{PP}=0.99)$ and weak support in MP analysis $(\mathrm{BF}=52 \%$, Figure 6$)$, but was paraphyletic in $\mathrm{ML}$ analysis with weak support $(\mathrm{BF}=51 \%$, Figure 5). The Ancylostomatoidea and the Strongyloidea were paraphyletic in all of the three phylogenetic analyses in this study; there was strong support for the paraphylies of these two superfamilies in Bayesian and MP analyses ( $\mathrm{PP}>0.96$, Figure 4; $\mathrm{BF}=99 \%$, Figure 5).

The 26 species of the suborder Spirurina included in this study were from three infraorders: Ascaridomorpha (14

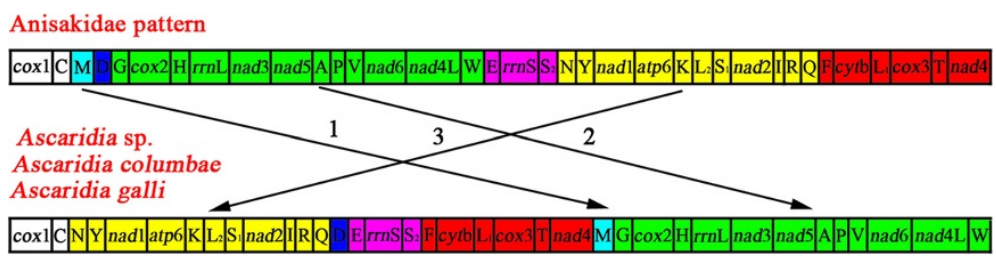

Figure 3 Rearrangement of mitochondrial genes in three Ascaridia species (pattern GA1) relative to the most common pattern of $\mathrm{mt}$ gene arrangement observed in nematodes (GA3). 


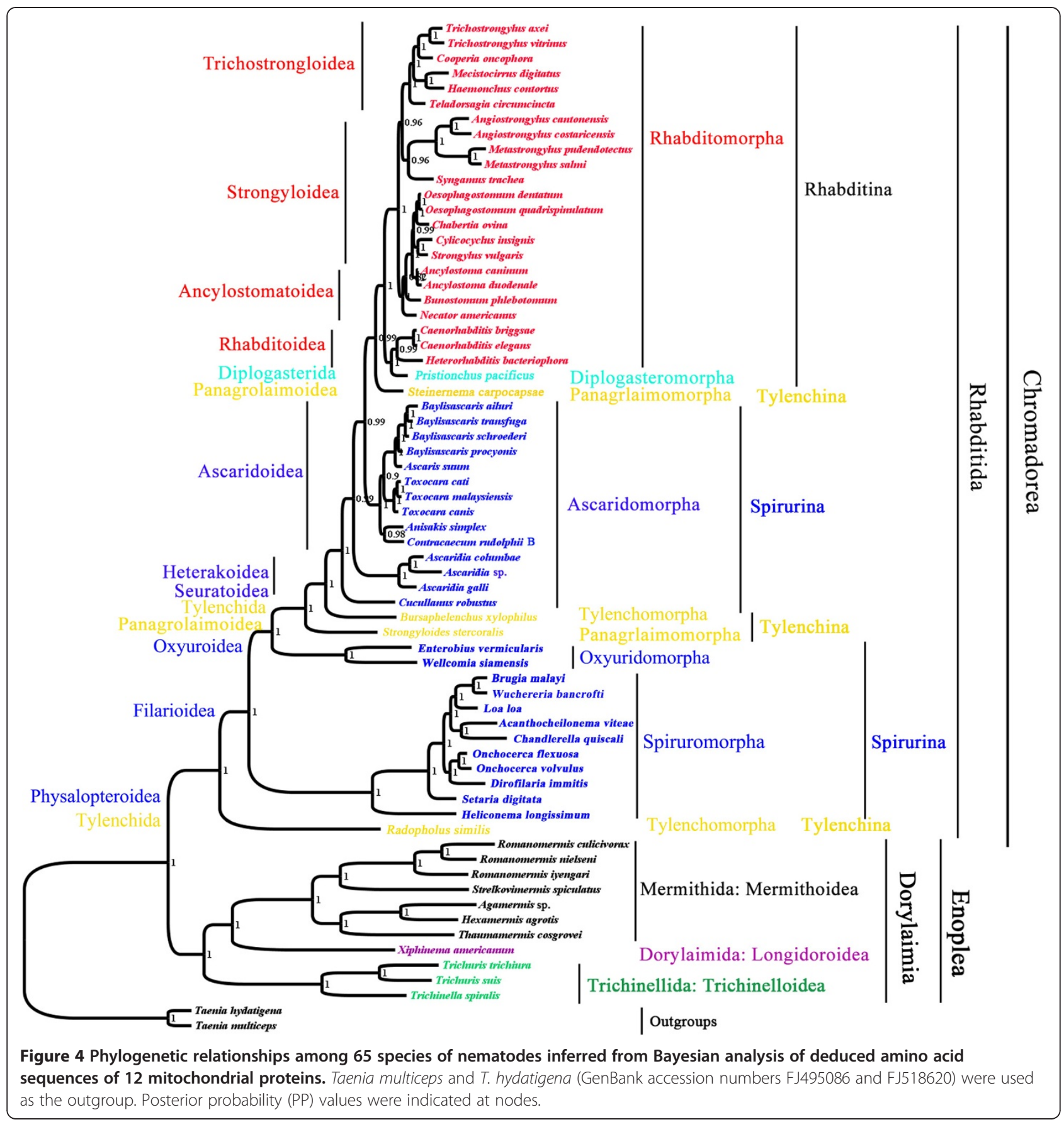

species), Oxyuridomorpha (2 species) and Spiruromorpha (10 species). The Oxyuridomorpha and the Spiruromorpha were both monophyletic with strong support in all of the three phylogenetic analyses $(\mathrm{PP}=1$, Figure $4 ; \mathrm{BF}=100 \%$, Figure $5 ; \mathrm{BF}=100 \%$, Figure 6). The Ascaridomorpha, however, was monophyletic only in ML analysis with moderate support $(B F=84 \%$, Figure 5$)$, and was paraphyletic in Bayesian analysis with strong support $(\mathrm{PP}=0.99$, Figure 4$)$ and $\mathrm{MP}$ analysis with weak support $(\mathrm{BF}=52 \%$, Figure 6). In both Bayesian and MP analyses, the 10 species of the superfamily Ascarodoidea of the infraorder Ascaridomorpha were more closely related to those of the Rhabditina and Steinernema carpocapsae (Tylenchina) than they were to the three Ascaridia species and Cucullanus robustus, which were also from the infraorder Ascaridomorpha. The three Ascaridia species, for which $\mathrm{mt}$ genomes were sequenced in this study, form a monoplyletic group with strong support in all of the three phylogenetic analyses (Figures 4, 5, 6). 


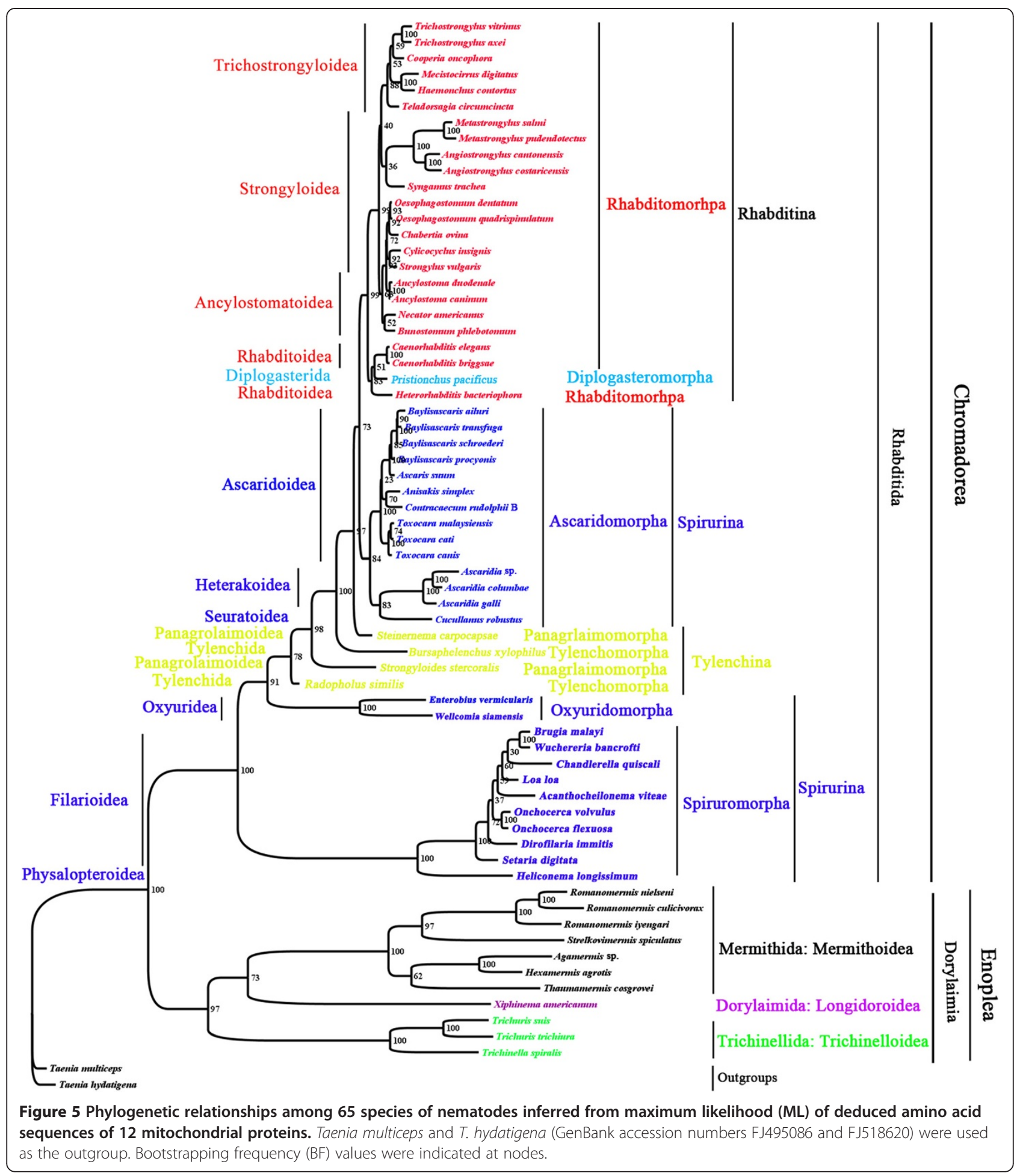

Cucullanus robustus was sister to Ascaridomorpha + Rhabditina + Steinernema carpocapsae in Bayesian analysis with strong support ( $\mathrm{PP}=1$, Figure 4). Cucullanus robustus, however, was sister the Ascaridia species with moderate support in ML analysis $(B F=83 \%$, Figure 5$)$ and weak support in MP analysis (55\%, Figure 6).
The four species of the suborder Tylenchina included in this study were from two infraorders: Panagrolaimorpha (2 species), and Tylenchomorpha (2 species). Both of these infraorders were paraphyletic in all of the three analyses ( $\mathrm{PP}>0.99$, Figure $4 ; \mathrm{BF}>57 \%$, Figure $5 ; \mathrm{BF}>51 \%$, Figure 6). 


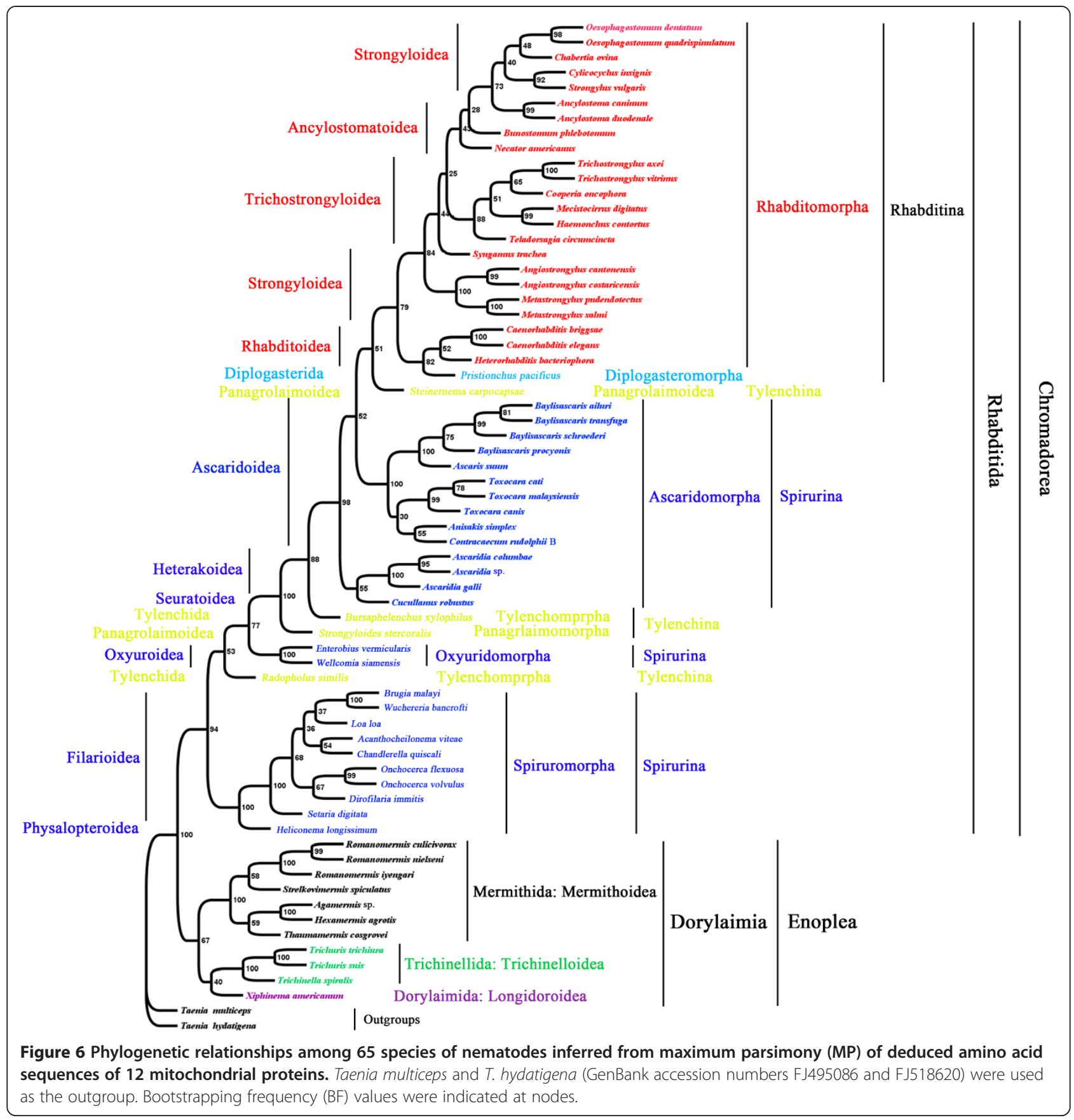

\section{Phylogenetic relationships within the subclass Dorylaimia}

The 11 species of the subclass Dorylaimia included in this study were from three orders: Mermithida (7 species), Dorylaimida (1 species), and Trichinellida (3 species). The Mermitida and the Trichinellida were both monophyletic with strong support in all of the three analyses $(\mathrm{PP}=1$, Figure 4; $\mathrm{BF}=100 \%$, Figure $5 ; \mathrm{BF}=100 \%$, Figure 6). Among the three orders, the Mermithida and the Dorylaimida were more closely related than either of them to the Trichocephalida, with strong support in Bayesian analysis ( $\mathrm{PP}=1$, Figure 4 ) and moderate support in $\mathrm{ML}$ analysis (BF $=73 \%$, Figure 5). The Dorylaimida was grouped with the Trichocephalida in MP analysis but the support to this grouping was weak $(\mathrm{BF}=40 \%$, Figure 6).

\section{Discussion}

Phylogenetic relationships among nematodes have been revised in the past two decades using sequences of nuclear small subunit (SSU) rRNA gene [12-14]. The current working hypothesis of Nematoda phylogeny incorporated evidence from both morphology, ecology and nuclear SSU rRNA gene sequence analyses [14,15]. 
Recently, Kang et al. [23] tested the hypothesis of the Nematoda phylogeny with the mt genome sequences of 25 species. Kang et al. [23] showed strong support to the monophyly of the class Chromadorea, represented by 16 species from the order Rhabditida; this study, however, could not establish the monophyly of the class Enoplea, represented by nine species from the subclass Dorylaimia. Park et al. [24] and Sultana et al. [25] expanded the taxon sampling and inferred phylogenies with $\mathrm{mt}$ genome sequences of 36 and 41 species of nematodes respectively. Park et al. [24] showed strong support for the monophylies of both Chromadorea and Enoplea. Sultana et al. [25], however, could not establish the monophyly of the class Enoplea in most of their analyses. A major difference between the mt genome phylogenies and the current working hypothesis of the Nematode phylogeny is on the monophyly of the suborder Spirurina, which includes Clade III nematodes proposed in Blaxter et al. [12]. In the current working hypothesis, the suborder Spirurina is monophyletic, which includes the infraorders Ascaridomorpha, Spiruromorpha and Oxyuridomorpha, whereas the infraorder Rhabditomorpha is in the suborder Rhabditina $[13,14]$. Further, Ascaridomorpha is most closely related to Spiruromorpha, whereas Oxyuridomorpha is sister to the group that includes Ascaridomorpha + Spiruromorpha. In the phylogenies inferred from $\mathrm{mt}$ genome sequences, however, Ascaridomorpha is most closely related to Rhabditomorpha; in most analyses, Oxyuridomorpha is sister to Ascaridomorpha + Rhabditomorpha, whereas Spiruromorpha is sister to the group that contains Ascaridomorpha, Rhabditomorpha and Oxyuridomorpha. Kang et al. [23], Park et al. [24] and Sultana et al. [25] contained much less taxa compared to previous phylogenetic studies on nematodes with nuclear SSU rRNA gene sequences (e.g. $>200$ taxa in Meldal et al. [14]). The novel phylogenetic relationship inferred from mt genome sequences, thus, needs to be tested further with more taxa from a wide range of nematode lineages.

In the present study, we sequenced the complete $\mathrm{mt}$ genomes of three Ascaridia species from the family Ascaridiidae of the superfamily Heterakoidea, which was not represented in previous studies (Kang et al. [23]; Park et al. [24]; Sultana et al. [25]). Furthermore, we inferred the phylogenetic relationships among 65 nematode species, for which complete mt genomes have been sequenced to date. Our analyses support the division of nematodes into two classes, Chromadorea and Enoplea, represented by the order Rhabditida and the subclass Dorylaimia, respectively, in the present study. Both the Rhabditida and the Dorylaimia were monophyletic with strong support, regardless the methods of phylogenetic analysis used. Within the order Rhabditida, the suborder Rhabditina was monophyletic; the other two suborders,
Spirurina and Tylenchina, however, were both paraphyletic in all of the three phylogenetic analyses in this study. Monophyly of the suborder Spirurina was well supported in nuclear SSU rRNA gene sequence analyses $[12,14]$, but was rejected in mt genome sequence analyses in Kang et al. [23], Park et al. [24], Sultana et al. [25] and the present study. Phylogenetic analyses of $\mathrm{mt}$ genome sequences in all of these four studies support strongly a close relationship between Ascaridomorpha and Rhabditomorpha to the exclusion of Oxyuridomorpha and Spiruromorpha. Apparently, additional markers for phylogenetic inference are required to resolve the controversy on the Spirurina between mt genome sequence phylogeny and nuclear SSU rRNA phylogeny.

Gene arrangement in $\mathrm{mt}$ genomes provides a source of information for phylogenetic inference, independent from $\mathrm{mt}$ genome sequences [18]. It is noteworthy that 10 species of Ascaridomorpha and 20 species of Rhabditomorpha included in our phylogenetic analyses share a common pattern of gene arrangement, GA3, in their mt genomes (Figure 2). GA3 is also present in Pristionchus pacificus, the only species from the infraorder Diplogasteromorpha, which is closely related to the species from the superfamily Rhabitoidea of the Rhabditomorpha (Figures 4, 5, 6). Indeed, GA3 is the most common pattern of $\mathrm{mt}$ gene arrangement observed in nematodes to date; nevertheless, this pattern is present only in species of the Ascaridomorpha, the Rhabditomorpha and the Diplogasteromorpha. The possibility that GA3 is ancestral to the phylum Nematoda can be rejected with confidence thanks to the discovery of mt gene arrangement pattern GA23 in three Trichinellida species [29,30]. GA23 shares obvious similarity with that of many arthropods and would resemble the ancestral pattern of mt gene arrangement of the phylum Nematoda more than any other patterns found in the nematodes. There is no evidence either that GA3 is ancestral to the class Chromadorea. Given the strong support to the close relationship between Ascaridomorpha and Rhabditomorpha + Diplogasteromorpha indicated by mt genome sequence analyses in the present study, the most parsimonious explanation is that GA3 is a shared derived character (i.e. synapomorphy) of the clade Ascaridomorpha + Rhabditomorpha + Diplogasteromorpha. The other six patterns, GA1, GA2, GA4, GA5, GA6 and GA25, observed in either Ascaridomorpha and Rhabditomorpha or in species closely related to these two infraorders, can be derived from GA3 by only a few rearrangement events (Figure 2), e.g. GA1, observed in the three Ascaridia species, can be converted from GA3 by three rearrangement events (see above).

Monophyly of the suborder Tylenchina could not be established previously in nuclear SSU RNA gene sequence analyses [14]. No species from this suborder were included in two previous analyses of $\mathrm{mt}$ genome 
sequences [23,24]. The present study included four species from the Tylenchina and indicated the paraphyly of this suborder. The positions of the four species of the Tylenchina change depending on the methods of phylogenetic inference used in this study. For instance, Steinernema carpocapsae is sister to the suborder Rhabditina in Bayesian analysis (Figure 4) and MP analysis (Figure 6); it is, however, sister to Ascaridomorpha + Rhabditomorpha + Diplogasteromorpha in ML analysis (Figure 5). Further test with more species from this suborder apparently is needed in order to clarify the phylogenetic position of the suborder Tylenchina. Indeed, a very recent study by Sultana et al. [25] included six species from the Tylenchina and showed the paraphyly of this suborder with strong support. The paraphyly of the infraorder Rhabditomorpha with respect to the Diplogasteromorpha will also need further test with expanded taxon sampling as only one species, Pristionchus pacificus, from the Diplogasteromorpha was included in the present study. No species from the subclass Enoplia, which has two orders and eight suborders [13], was included in our analyses. For the subclass Chromadoria, all of the species included in this study were from the order Rhabditida whereas the other five orders, Plectida, Araeolaimida, Monhysterida, Desmodorida, and Chromadorida, were not represented. Expanding taxon sampling from these lineages of nematodes is clearly the next step for phylogenetic studies of nematodes with $\mathrm{mt}$ genome sequences.

\section{Conclusions}

We sequenced the complete $\mathrm{mt}$ genomes of three Ascaridia species (family Ascaridiidae) that infest chickens, pigeons and parrots, respectively. These species have an identical arrangement of mt genes to each other but differ substantially from other nematodes. Phylogenetic analyses of the $\mathrm{mt}$ genome sequences of the Ascaridia species, in combination with 62 other nematode species, support the monophylies of the subclass Dorylaimia; the orders Rhabditida, Trichinellida and Mermithida; the suborder Rhabditina; and the infraorders Spiruromorpha and Oxyuridomorpha. Analyses of mt genome sequences, however, reject the monophylies of the suborders Spirurina and Tylenchina, and the infraorders Rhabditomorpha, Panagrolaimomorpha and Tylenchomorpha. Monophyly of the infraorder Ascaridomorpha varies depending on the methods of phylogenetic analysis. The Ascaridomorpha was more closely related to the infraorders Rhabditomorpha and Diplogasteromorpha (suborder Rhabditina) than they were to the other two infraorders of the Spirurina: Oxyuridorpha and Spiruromorpha. The closer relationship among Ascaridomorpha, Rhabditomorpha and Diplogasteromorpha was also supported by a shared common pattern of mitochondrial gene arrangement. Analyses of mitochondrial genome sequences and gene arrangement in the current study and several previous studies have provided novel insights into the phylogenetic relationships among several major lineages of nematodes. Many lineages of nematodes, however, are underrepresented or not represented in these analyses. Expanding taxon sampling is necessary for future phylogenetic studies of nematodes with mt genome sequences.

\section{Methods}

\section{Ethics statement}

This study was approved by the Animal Ethics Committee of Lanzhou Veterinary Research Institute, Chinese Academy of Agricultural Sciences (Approval No. LVRIAEC2011-009). The animals, from which the nematodes were collected postmortem, were handled in strict accordance with good animal practices required by the Animal Ethics Procedures and Guidelines of the People's Republic of China.

\section{Sample collection and DNA extraction}

Adult Ascaridia galli were obtained from naturally infected chickens in Hunan province, China. Adult $A$. columbae and an undescribed Ascaridia sp. [hereafter Ascaridia sp. (GHL-2012)] were obtained from naturally infected pigeons and parrots in Guangdong province, China. These nematodes were washed in physiological saline, identified preliminarily to species based on host preference, morphological characters and predilection sites [31-33], fixed in 70\% ethanol, and stored at $-20^{\circ} \mathrm{C}$.

Total genomic DNA was isolated from individual nematodes using sodium dodecyl sulphate/proteinase $\mathrm{K}$ treatment, followed by spin-column purification (Wizard ${ }^{\circ} \mathrm{SV}$ Genomic DNA Purification System, Promega). In order to independently verify the identity of the specimen, the region spanning ITS-1, 5.8S rRNA gene and ITS-2 was amplified from each individual nematode by PCR using previously reported primers [34] and sequenced directly.

\section{PCR amplification of the mitochondrial genomes of Ascaridia species}

We amplified fragments (400-500 bp) of cox1, nad1 and nad4 genes by PCR using conserved primers (Table 2). The amplicons were sequenced from both directions using BigDye terminator v3.1 on ABI PRISM 3730 platform. We then designed specific primers from these fragments for long PCR amplification (Table 3). We amplified the entire mt genome of individual specimens of A. galli, A. columbae and Ascaridia sp. (GHL-2012) by long PCR in three or four overlapping fragments, respectively. The three overlapping long-PCR fragments for $A$. galli were between $\operatorname{cox} 1$ and nad1 $(\sim 2.5 \mathrm{~kb})$, between nad1 and nad4 ( 7.5 kb), and between nad4 and $\operatorname{cox} 1(\sim 5.0 \mathrm{~kb})$. The four overlapping long-PCR fragments for A. columbae and Ascaridia sp. (GHL-2012) 
Table 2 Primers used to amplify short-PCR fragments from Ascaridia galli, Ascaridia columbae and Ascaridia sp

\begin{tabular}{|c|c|c|}
\hline Name of primer & Sequence $\left(5^{\prime}\right.$ to $\left.3^{\prime}\right)$ & Reference \\
\hline \multicolumn{3}{|l|}{ For A. galli } \\
\hline \multicolumn{3}{|l|}{ pcox 1} \\
\hline AGCoxiF & GAAGTTTGTATTTGACTGGTAAGAA & This study \\
\hline AGCoxiR & CAGTGAGACCACCAATAGTAAACAA & This study \\
\hline \multicolumn{3}{|l|}{ pnad1 } \\
\hline JB11 & AGATTCGTAAGGGGCCTAATA & [36] \\
\hline JB12 & ACCACTAACTAATTCACTTC & [36] \\
\hline \multicolumn{3}{|l|}{ pnad4 } \\
\hline AGNad4F & СТTATTATTTAATTTTATGCTGCT & This study \\
\hline AGNad4R & AAGCGGCTAAAGCCTTAGCATCACT & This study \\
\hline \multirow{2}{*}{\multicolumn{3}{|c|}{$\begin{array}{l}\text { For A. columbae } \\
\text { and Ascaridia sp. } \\
\text { pcox } 2\end{array}$}} \\
\hline & & \\
\hline ACCOX2F & TTAAAGTTGTTGTATTATTATGGTTT & This study \\
\hline ACCOx2R & AAAATACACCAACCACAGGAAAACT & This study \\
\hline \multicolumn{3}{|l|}{ pnad1 } \\
\hline JB11 & AGATTCGTAAGGGGCCTAATA & [36] \\
\hline JB12 & ACCACTAACTAATTCACTTTC & [36] \\
\hline \multicolumn{3}{|l|}{ pcox3 } \\
\hline ACCOX3F & TGGTATTTCTGGACTTTTTTGAT & This study \\
\hline ACCox3R & CCAAACTACATCTACAAAATGCCAA & This study \\
\hline
\end{tabular}

were between cox1 and nad1 ( 2.5 kb), between nad1 and $\operatorname{nad} 3(\sim 5 \mathrm{~kb})$, between $\operatorname{nad} 3$ and $\operatorname{cox} 2(\sim 2.5 \mathrm{~kb})$ and between $\operatorname{cox} 2$ and $\operatorname{cox} 1(\sim 5.0 \mathrm{~kb})$. Each long-PCR reaction $(25 \mu \mathrm{l})$ contains $2.5 \mu \mathrm{L} 2 \mathrm{mM} \mathrm{MgCl}_{2}, 4.0 \mu \mathrm{L}$ $0.2 \mathrm{mM}$ each of dNTPs, $2.5 \mu \mathrm{L} 2.5 \mu \mathrm{l} 10 \times$ rTaq buffer, $0.25 \mu \mathrm{L} 2.5 \mu \mathrm{M}$ of each primer, $0.25 \mu \mathrm{L} 1.25 \mathrm{U}$ rTaq polymerase (Takara), and $2 \mu \mathrm{l}$ of total genomic DNA. The PCR conditions were: $92^{\circ} \mathrm{C}$ for $2 \mathrm{~min}$ (initial denaturation), then $92^{\circ} \mathrm{C}$ for $10 \mathrm{sec}$ (denaturation), $48-51^{\circ} \mathrm{C}$ for $30 \mathrm{sec}$ (annealing) and $60^{\circ} \mathrm{C}$ for $10 \mathrm{~min}$ (extension) for 10 cycles, followed by $92^{\circ} \mathrm{C}$ for $10 \mathrm{sec}, 48-51^{\circ} \mathrm{C}$ for $30 \mathrm{sec}$, and $60^{\circ} \mathrm{C}$ for $10 \mathrm{~min}$ for 20 cycles and a final extension at $60^{\circ} \mathrm{C}$ for $10 \mathrm{~min}$. PCR amplicons were column-purified and then sequenced using a primer walking strategy [35].

\section{Sequence assembly and mitochondrial genome annotation}

Sequence reads of A. galli, A. columbae and Ascaridia sp. (GHL-2012) were assembled with ContigExpress program of the Vector NTI software package version 6.0 (Invitrogen, Carlsbad, CA). The mt genome sequences of the Ascaridia species were aligned with those of other nematode species available in GenBank using Clustal X 1.83 [37] to infer gene boundaries. The open-reading frames and codon usage profiles of protein-coding genes were analysed by the Open Reading Frame Finder
Table 3 Primers used to amplify long-PCR fragments from Ascaridia galli, Ascaridia columbae and Ascaridia sp

\begin{tabular}{|c|c|}
\hline Name of primer & Sequence $\left(5^{\prime}\right.$ to $\left.3^{\prime}\right)$ \\
\hline \multicolumn{2}{|l|}{ For A. galli } \\
\hline AGC1N1F & ATAGAAGTTTGTATTTGACTGGTAAGAAGGAGGT \\
\hline AGC1N1R & CACAATACCAGTAACCAAAGTAGCATAAACAG \\
\hline AGN1N4F & TAAGTTGTTGAAGAAGGAGCAGGAGAGT \\
\hline AGN1N4R & CAAAAATGGAAAAGAACACAAAGCAGCA \\
\hline AGN4C1F & TITTATGCTGCTTTGTGTTCTITTCCA \\
\hline AGN4C1R & CCAAATAAAGTTGCCAGCCACCTAAA \\
\hline \multicolumn{2}{|l|}{ For A. columbae } \\
\hline ACC1N1F & AGTTGGACTGTTTATCCGCCTITGA \\
\hline ACC1N1R & ATTTCATAAGACACTCTCTGACCTC \\
\hline ACN1C3F & GCCAGAGGTCAGAGAGTGTCTTATG \\
\hline ACN1C3R & СTTGCTTCACTATACTCTATTGCCTGT \\
\hline $\mathrm{ACC} 3 \mathrm{C} 2 \mathrm{~F}$ & CAGGCAATAGAGTATAGTGAAGCAA \\
\hline $\mathrm{ACC} 3 \mathrm{C} 2 \mathrm{R}$ & ATAGAAGGCACAGCCCAAGAATGAA \\
\hline $\mathrm{ACC} 2 \mathrm{C} 1 \mathrm{~F}$ & TAGTATGTGATGTTTGGGAATGCTT \\
\hline $\mathrm{ACC} 2 \mathrm{C} 1 \mathrm{R}$ & CTITACACCAGTAGGCACAGCGAT \\
\hline \multicolumn{2}{|l|}{ For Ascaridia sp. } \\
\hline ACC1N1F & AGTTGGACTGTTTATCCGCCTITGA \\
\hline ACC1N1R & ATTTCATAAGACACTCTCTGACCTC \\
\hline ASN1C3F & GGTCAGAGGGTTTCTTATGAGATTGCT \\
\hline ASN1C3R & CAACCGAACAATCTITATTACTCAACA \\
\hline $\mathrm{ASC} 3 \mathrm{C} 2 \mathrm{~F}$ & TGTTGAGTAATAAAGATTGTTCGGTTG \\
\hline ASC3C2R & ACCAGGAATGTCACCATACTCATAACT \\
\hline $\mathrm{ASC} 2 \mathrm{C} 1 \mathrm{~F}$ & TGGAGGTTGATAATCGTTGTGTTITGC \\
\hline ASC2C1R & CACAACAACAAAGGCTGAAAAACCATC \\
\hline
\end{tabular}

(http://www.ncbi.nlm.nih.gov/gorf/gorf.html) using the invertebrate mitochondrial genetic code, and subsequently compared with those of Ascaris suum [38] and Contracaecum rudolphii B [28]. Sequences of proteincoding genes were translated into amino acid sequences using the invertebrate mitochondrial genetic code in MEGA 5.0 [39]. Translation initiation and termination codons were identified by comparison with those of the nematodes reported previously $[27,28]$. The secondary structures of 22 tRNA genes were predicted using tRNAscan-SE [40] with manual adjustment [41]. Tandem repeats in the non-coding regions were found using Tandem Repeat Finder program (http://tandem. bu.edu/trf/trf.html) [42].

\section{Phylogenetic analyses}

Considering the high degree of intraspecific variation in nucleotide sequences of $\mathrm{mt}$ genes of nematodes [43], we used the deduced amino acid sequences of mt proteins for phylogenetic analyses. Amino acid sequences were 
deduced from the sequences of the $12 \mathrm{mt}$ proteincoding genes common for all of the 65 nematode species and two outgroup species included in this study. The deduced amino acid sequences of each of the $12 \mathrm{mt}$ proteins of these species were aligned individually and then were concatenated into a single alignment. Ambiguous sites and regions in the alignment were excluded using Gblocks (http://molevol.cmima.csic.es/castresana/Gblocks_ server.html) [44] with the default parameters. Two Taenia cestodes (T. multiceps and T. hydatigena, GenBank accession number FJ495086 and FJ518620, respectively) were used as the outgroup.

Phylogenetic analyses were conducted using three methods: Bayesian, maximum likelihood (ML), and maximum parsimony (MP). The MtArt model of amino acid evolution [45] was selected as the most suitable model of evolution by ProtTest 2.4 [46] based on the Akaike information criterion (AIC). Bayesian analysis was with MrBayes 3.1.1 [47]. As MtArt model is not implemented in the current version of MrBayes, an alternative model, MtREV, was used in Bayesian analysis. Four independent Markov chains were run for 1,000,000 metropoliscoupled MCMC generations, sampling a tree every 100 generations. The first 2,500 trees represented burn-in, and the remaining trees were used to calculate Bayesian posterior probabilities (PP). Maximum likelihood (ML) analysis was performed using PhyML 3.0 [48] with the MtArt model. 100 bootstrap replicates were run and bootstrapping frequencies (BF) were calculated. MP analysis was with PAUP* 4.0b10 [49]; indels were treated as missing characters. A total of 1,000 random addition searches using tree bisection-reconnection (TBR) branch swapping were performed for each MP analysis. Bootstrapping frequency (BF) was calculated from 1,000 bootstrap replicates with 10 random additions per replicate in PAUP. Phylograms were drawn using FigTree v.1.31 (http://tree.bio.ed.ac.uk/software/figtree/).

\section{Competing interests}

The authors declare no competing interests.

\section{Authors' contributions}

XQZ, RS and GHL designed the research. GHL and JYL performed the research. DHZ contributed reagents/materials/analyses. GHL, RS and HL analyzed the data. RS, GHL and XQZ wrote the manuscript. All authors have read and approved the final manuscript.

\section{Acknowledgements \\ This work was supported, in part, by the International Science \& Technology Cooperation Program of China (Grant No. 2013DFA31840) and the Science Fund for Creative Research Groups of Gansu Province (Grant No. 1210RJIA006) to XQZ. RS acknowledges the funding support from the Australian Research Council (Discovery Project DP120100240) and the Australian Government (Australia-China Science \& Research Fund, ACSRF00980).}

\section{Author details}

'State Key Laboratory of Veterinary Etiological Biology, Key Laboratory of Veterinary Parasitology of Gansu Province, Lanzhou Veterinary Research Institute, Chinese Academy of Agricultural Sciences, Lanzhou, Gansu Province
730046, People's Republic of China. ${ }^{2}$ College of Veterinary Medicine, Hunan Agricultural University, Changsha, Hunan Province 410128, People's Republic of China. ${ }^{3}$ Genecology Research Centre, University of the Sunshine Coast, Queensland 4558, Australia. ${ }^{4}$ Department of Entomology, China Agricultural University, Beijing 100193, People's Republic of China.

Received: 17 November 2012 Accepted: 19 June 2013 Published: 21 June 2013

\section{References}

1. Dieterich C, Sommer RJ: How to become a parasite - lessons from the genomes of nematodes. Trends Genet 2009, 25:203-209.

2. Schneider A: Monoden. Berlin: Georg Reimer; 1866:357.

3. Cobb NA: The orders and classes of nemas. Contrib Sci Nematol 1919, 8:213-216.

4. Filipjev IN: Classification of freeliving Nematoda and their relations to parasitic forms. J Parasitol 1929, 15:281-282.

5. Chitwood BG: "A revised classification of the Nematoda". In Papers on helminthology, 30 year jubileum. Edited by Skrjabin KJ. Moscow: All-Union Lenin Academy of Agricultural Sciences; 1937:67-79.

6. Maggenti AR: Comparative morphology in nemic phylogeny. In The Lower Metazoa: Comparative Biology and Phylogeny. Edited by Dougherty EC, Brown ZN, Hanson ED, Hartman WD. Berkeley: University of California Press; 1963:273-282.

7. Maggenti AR: Nematode Higher Classification as Influenced by Species and Family Concepts. In concepts in nematodesystematics: Academic Press, London; 1983.

8. Inglis WG: An outline classification on the Phylum Nematoda. Aust J Zool 1983, 31:243-255.

9. Anderson RC: Nematode Parasites of Vertebrates: Their Development and Transmission. Wallingford: CAB International; 1992.

10. Lorenzen S: The Phylogenetic Systematics of Free living Nematodes. London: The Ray Society; 1994.

11. Adamson M: Phylogenetic analysis of the higher classification of the Nematoda. Can J Zool 1987, 65:1478-1482.

12. Blaxter ML, De Ley P, Garey JR, Liu LX, Scheldeman P, Vierstraete A, Vanfleteren JR, Mackey LY, Dorris M, Frisse LM, Vida JT, Thomas WK: A molecular evolutionary framework for the phylum Nematoda. Nature 1998, 392:71-75.

13. De Ley P, Blaxter M: Systematic position and phylogeny. In The Biology of Nematodes. Edited by Lee DL. London and New York: Taylor \& Francis; 2002:1-30.

14. Meldal BH, Debenham NJ, De Ley P, De Ley IT, Vanfleteren JR, Vierstraete AR, Bert W, Borgonie G, Moens T, Tyler PA, Austen MC, Blaxter ML, Rogers AD, Lambshead PJ: An improved molecular phylogeny of the Nematoda with special emphasis on marine taxa. Mol Phylogenet Evol 2007, 42:622-636.

15. Wolstenholme DR: Animal mitochondrial DNA, structure and evolution. Int Rev Cytol 1992, 141:173-216.

16. Boore JL: Animal mitochondrial genomes. Nucleic Acids Res 1999, 27:1767-1780.

17. Lavrov DV: Key transitions in animal evolution: a mitochondrial DNA perspective. Integr Comp Biol 2007, 47:734-743.

18. Boore JL, Brown WM: Big trees from little genomes: mitochondrial gene order as a phylogenetic tool. Curr Opin Genet Dev 1998, 8:668-674.

19. Shao R, Barker SC: Mitochondrial genomes of parasitic arthropods: implications for studies of population genetics and evolution. Parasitology 2007, 134:153-167.

20. Boore $J \mathrm{~L}$, Lavrov DV, Brown WM: Gene translocation links insects and crustaceans. Nature 1998, 392:667-668.

21. Boore JL, Brown WM: Mitochondrial genomes of Galathealinum, Helobdella, and Platynereis: sequence and gene arrangement comparisons indicate that Pogonophora is not a phylum and Annelida and Arthropoda are not sister taxa. Mol Biol Evol 2000, 17:87-106.

22. Lavrov DV, Brown WM, Boore JL: Phylogenetic position of the Pentastomida and (pan) crustacean relationships. Proc Biol Sci 2004, 271:537-544.

23. Kang S, Sultana T, Eom KS, Park YC, Soonthornpong N, Nadler SA, Park JK: The mitochondrial genome sequence of Enterobius vermicularis (Nematoda: Oxyurida)-an idiosyncratic gene order and phylogenetic information for chromadorean nematodes. Gene 2009, 429:87-97.

24. Park JK, Sultana T, Lee SH, Kang S, Kim HK, Min GS, Eom KS, Nadler SA: Monophyly of clade III nematodes is not supported by phylogenetic 
analysis of complete mitochondrial genome sequences. BMC Genomics 2011, 12:392.

25. Sultana T, Kim J, Lee SH, Han H, Kim S, Min GS, Nadler SA, Park JK: Comparative analysis of complete mitochondrial genome sequences confirms independent origins of plant-parasitic nematodes. BMC Evol Biol 2013, 13:12.

26. Abdelqader A, Gauly M, Wollny CB, Abo-Shehada MN: Prevalence and burden of gastrointestinal helminthes among local chickens, in northern Jordan. Prevent Vet Med 2008, 85:17-22.

27. Liu GH, Wu CY, Song HQ, Wei SJ, Xu MJ, Lin RQ, Zhao GH, Huang SY, Zhu $X Q$ : Comparative analyses of the complete mitochondrial genomes of Ascaris lumbricoides and Ascaris suum from humans and pigs. Gene 2012, 492:110-116.

28. Lin RQ, Liu GH, Zhang Y, D'Amelio S, Zhou DH, Yuan ZG, Zou FC, Song $\mathrm{HQ}$, Zhu XQ: Contracaecum rudolphii B: gene content, arrangement and composition of its complete mitochondrial genome compared with Anisakis simplex s.l. Exp Parasitol 2012, 130:135-140.

29. Liu GH, Gasser RB, Su A, Nejsum P, Peng L, Lin RQ, Li MW, Xu MJ, Zhu $X Q$ : Clear genetic distinctiveness between human- and pig-derived Trichuris based on analyses of mitochondrial datasets. PLOS Negl Trop Dis 2012, 6:e1539.

30. Lavrov DV, Brown WM: Trichinella spiralis mtDNA: a nematode mitochondrial genome that encodes a putative ATP8 and normally structured tRNAS and has a gene arrangement relatable to those of coelomate metazoans. Genetics 2001, 157:621-637.

31. Ramadan HH, Abouznada NY: Morphology and life history of Ascaridia galli in the Domestic Fowl that are raised in Jeddah. J K A U Science 1992, 4:87-99.

32. Wehr EE, Hwang JC: The life cycle and morphology of Ascaridia columbae (Gmelin, 1790) Travassos, 1913 (Nematoda:Ascarididae) in the Domestic Pigeon (Columba livia domestica). J Parasitol 1964, 50:131-137

33. Kajerova V, Barus V, Literak I: New records of Ascaridia platycerium (Nematodes) in parrots (Psittaciformes). Vet Med-Czech 2004, 49:237-241.

34. Zhu X, Chilton NB, Jacobs DE, Boes J, Gasser RB: Characterisation of Ascaris from human and pig hosts by nuclear ribosomal DNA sequences. Int J Parasitol 1999, 29:469-478.

35. Hu M, Jex AR, Campbell BE, Gasser RB: Long PCR amplification of the entire mitochondrial genome from individual helminths for direct sequencing. Nature Protoc 2007, 2:2339-2344.

36. Bowles J, McManus DP: NADH dehydrogenase 1 gene sequences compared for species and strains of the genus Echinococcus. Int J Parasitol 1993, 23:969-972.

37. Thompson JD, Gibson TJ, Plewniak F, Jeanmougin F, Higgins DG: The Clustal $X$ windows interface: flexible strategies for multiple sequence alignment aided by quality analysis tools. Nucleic Acids Res 1997, 25:4876-4882.

38. Okimoto R, Macfarlane JL, Clary DO, Wolstenholme DR: The mitochondrial genomes of two nematodes, Caenorhabditis elegans and Ascaris suum. Genetics 1992, 130:471-498.

39. Tamura K, Peterson D, Peterson N, Stecher G, Nei M, Kumar S: MEGA5: molecular evolutionary genetics analysis using maximum likelihood, evolutionary distance, and maximum parsimony methods. Mol Biol Evol 2011, 28:2731-2739.

40. Lowe TM, Eddy SR: tRNAscan-SE: a program for improved detection of transfer RNA genes in genomic sequence. Nucleic Acids Res 1997, 25:955-964

41. Hu M, Chilton NB, Gasser RB: The mitochondrial genomes of the human hookworms, Ancylostoma duodenale and Necator americanus (Nematoda: Secernentea). Int J Parasitol 2002, 32:145-158.

42. Benson G: Tandem repeats finder: a program to analyze DNA sequences. Nucleic Acids Res 1999, 27:573-580.

43. Hu M, Gasser RB: Mitochondrial genomes of parasitic nematodes progress and perspectives. Trends Parasitol 2006, 22:78-84.

44. Talavera G, Castresana J: Improvement of phylogenies after removing divergent and ambiguously aligned blocks from protein sequence alignments. Syst Biol 2007, 56:564-577.

45. Abascal F, Posada D, Zardoya R: MtArt: a new model of amino acid replacement for Arthropoda. Mol Biol Evol 2007, 24:1-5.
46. Abascal F, Zardoya R, Posada D: ProtTest: selection of best-fit models of protein evolution. Bioinformatics 2005, 21:2104-2105.

47. Ronquist F, Huelsenbeck JP: MrBayes 3: Bayesian phylogenetic inference under mixed models. Bioinformatics 2003, 19:1572-1574.

48. Guindon S, Gascuel O: A simple, fast, and accurate algorithm to estimate large phylogenies by maximum likelihood. Syst Biol 2003, 52:696-704

49. Swofford DL: Paup*: Phylogenetic analysis using parsimony, version 4.0610 Sunderland, MA: Sinauer Associates; 2002.

doi:10.1186/1471-2164-14-414

Cite this article as: Liu et al:: The complete mitochondrial genomes of three parasitic nematodes of birds: a unique gene order and insights into nematode phylogeny. BMC Genomics 2013 14:414.

\section{Submit your next manuscript to BioMed Central and take full advantage of:}

- Convenient online submission

- Thorough peer review

- No space constraints or color figure charges

- Immediate publication on acceptance

- Inclusion in PubMed, CAS, Scopus and Google Scholar

- Research which is freely available for redistribution 